\title{
CALL in the Form of Simulation Games: Teaching English Vocabulary and Pronunciation through Sims
}

\author{
Hussein Meihami $^{1, *}$, Bahram Meihami ${ }^{2}$, Zeinab Varmaghani ${ }^{3}$ \\ 1Department of English Language Teaching, Ghorveh Branch, Islamic Azad University, Ghorveh, Iran \\ ${ }^{2}$ Department of Accounting, Ghorveh Branch, Islamic Azad University, Ghorveh \\ 3BA Student of Primary Education, Ghorveh Branch, Islamic Azad University, Gr eh, Iran \\ *E-mail address: hussein.meihami@yahoo.com

\section{ABSTRACT}

When discussing the current state of art with regard to second language learning one thing is blinking sharply. pedegugical context for sailors and mariners to learn E ish as a sec nd or foreign language is the essence of this study. Simulation games show potential no for eno ging and entertaining users, but also in promoting language learning. In this rese the surves ufect of simulation Games on sailor and mariners' English vocabulary and pronunci tom ning of Khoramshahr Navy University. The results clearly showed that these kinds of games h ve sigy cant impact of learners, especially when they learn English as ESP like the sailomand mari rs.

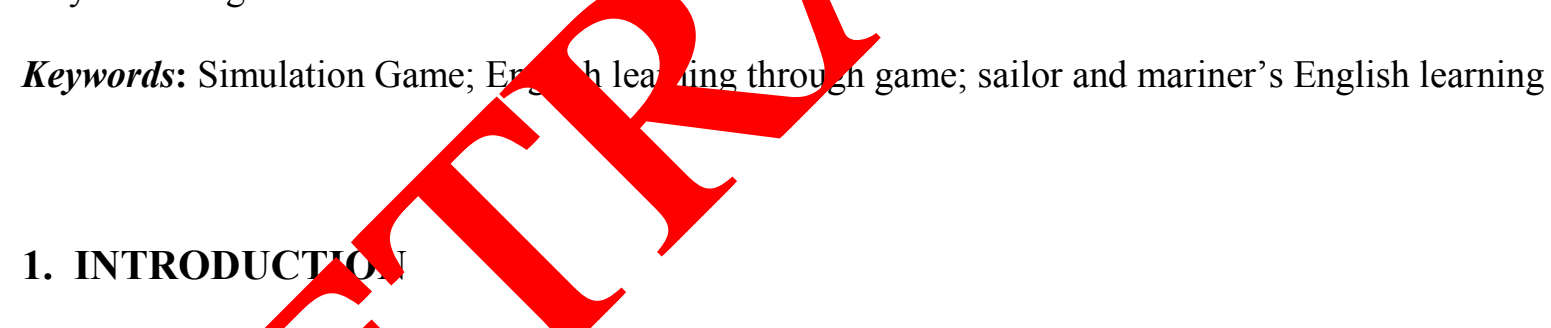

In rece years here has been a growing body of research on new language learning techniques. Us ame $h$ been the subject of many papers and discussions over the recent decade gam of bofined as an activity that contains some or all of the following elep ents: dles, gy challenges, fantasy, mystery, curiosity, competition, and skill (Ga At \& Diskell, 2002; Randel, Morris, Wetzel, \& Whitehill, 1992). Games that are adapto nd used for educational purposes aim to have players achieve a specific learning outcome the goal of the game ( Garris et al., 2002 ). Over the past decade, educators have reported us.ng games as instructional tools in a variety of disciplines.

Koether (2003) described the use of a "name game" to teach students chemical information; Gublo (2003) used a "trivia game" to teach laboratory safety methods. Gaming is a characteristic of human nature, hence it can be claimed that the history of gaming goes back to the beginning of the history of human being (Demirbilek, Yilmaz, \& Tamer, 2010). According to Juul (2003) a game is a rule based formal system with a variable and quantifiable outcome, where different outcomes are assigned different values, the player exerts effort in 
order to influence the outcome, the player feels attached to the outcome, and the consequences of the activity are optional and negotiable.

The game definition Juul proposed contains six parameters: 1) Rules: games are rulebased. 2) Outcome: games have variable, quantifiable outcomes. 3) Value: that the different potential outcomes of the game are assigned different values, some being positive, some being negative. 4) Effort: that the player invests effort in order to influence the outcome. 5) Player's attachment: that the players are attached to the outcomes of the game in the sense that a player will be the winner and happy if a positive outcome happens, and loser and unhappy if a negative outcome happens 6) Negotiable consequences: the same game can be played with or without real-life consequences (Ang \& Zaphiris, 2008).

Educational games are activities that provide students with the opportur to reinfor the previous knowledge by repeating it in a more comfortable environment. roduca nal gam are software that helps students to learn the lesson subjects and to develop neir problo oly ing skills by using their desire and enthusiasm to play (Donmus, 2010).

\section{1. Review of Literature}

Using Simulation games has been a much thought oou t rarely ad work on in language learning. Educational software developers hav suggle present a substantial amount of content; context and feedback without sacrif cing the degree control game players (Buckingham \& Scanlon, 2003). There are sever instances of games used in language learning (Seay, 1997; Kirriemuir, 2002), as well as roponents ff using computer games to educate (Prensky, 2002).

deHaan (2011) has investigated tead and leanng English through digital game projects. Two completed extracurricular proj cts, don constructionist learning and media literacy theories and practices, are described n 1 is pa ser: game design and game magazine creation. The action research proj imed to zuide students towards a better understanding of games' formal features and chnol sies thro of their active creation of games and gamerelated media, and to improve ir written English language skills. In general, students learned and pra aced a ety of language and technology skills with the design projects. The projects vated the dents, challenged the students, and provided many opportunities for aut entic cussions in the foreign language.

deHaan, $\mathrm{R} \ldots$ and Kun (2010) have investigated the effect of interactivity with a music video $g$ me on econd lan, aage vocabulary recall. Their experimental study investigated to what degre ide game interactivity would help or hinder the noticing and recall of second language voca ry. Eis aty randomly-selected Japanese university undergraduates were paire 1 on 5 . English language and game proficiencies. One subject played an Ep sh-la guage my sc video game for 20 minutes while the paired subject watched the game simu another monitor. Following game play, a vocabulary recall test, a cognitive load mo re, an experience questionnaire, and a two week delayed vocabulary recall test were administer

Results were analyzed using paired samples $t$ tests and various analyses of variance. Both the players and the watchers of the video game recalled vocabulary from the game, but the players recalled significantly less vocabulary than the watchers. This seems to be a result of the extraneous cognitive load induced by the interactivity of the game; the players perceived the game and its language to be significantly more difficult than the watchers did. Players also reported difficulty simultaneously attending to game play and vocabulary. Both players and watchers forgot significant amounts of vocabulary over the course of the study. 
Wang (2010) has studied the effect of using communicative language games in teaching and learning English in Taiwanese primary schools. The aim of his study was to examine the use of communicative language games for teaching and learning English in Taiwanese elementary schools. The participants were 150 teachers teaching in Taiwanese primary schools. The instrument used was a survey questionnaire about participants 'perspectives on the use of communicative language games in English lessons.

The results of the study provided encouraging evidence to indicate that Taiwanese elementary school teachers generally appreciated the benefits and value of communicative game activities in the teaching of English language. The findings also suggested thotwhen facing students with different backgrounds, learning styles, needs, and expectati $11 \mathrm{~S}$, tean s should be aware to take learners 'individual variations into account and be more vible in th use of communicative games in order to maximize educational effect It is oped th communicative language games will attract more attention and will be ar plied moro rely in the classroom with more positive attitudes on the part of language tea ars.

Turgut and Irgin (2009) have studied young learners' langy oe ving via omputer games in Turkey. This qualitative research based on phenomeno ogical th tical ramework investigates young learners'experiences of language learnin playing aputer games in internet cafes. The data was collected through observatio s and ni-structured interviews and analyzed through phenomenological data analysis ups. The resu indicated that young learners'playing online games promotes language lez ning and especial $y$ vocabulary skills.

\section{1. 1. Vocabulary}

Vocabulary learning is often perceive boring o, warners, especially for those who grew up in the digital age. The Simulation an onened up a world of possibilities for improving the vocabularies of young learners. vasing ormulation Game, teachers and parents can ensure that their young learner prepare for the adventure of reading and writing. Our generation may not have had ac ess to rmal vo yulary instruction in our preschool and early elementary years, but vocab'ra, ss computer. In playing con putur gà young people are making use of vocabulary for their own purposes, in com and pleast. what Sefton-Green o scrib s 'a wider ecology of education where schools, home, playtime, the library and manum all pla oart' (p.19).

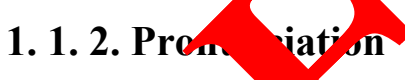

in th "rea vorld" often be very daunting for easily intimidated students. Role plays and use it the rear world." Video games are another avenue for "experimentation in a safe "virtual a ronment"' (Kirriemuir, 2002). Learners may be hesitant to participate in language classes because of not wanting to make a mistake in front of their peers, but may be more willing to interact with a Simulation Games in order to gain valuable linguistic feedback and practice with language before applying their knowledge in the "real world." As Simulation Games are interactive, they are able to immediately give valuable linguistic feedback. In The Sims, players control characters' actions and interactions by selecting text commands. If, for example, a player confuses "flirt" and "talk," it will become quickly apparent to the player that his/her linguistic competency is lacking and the player will have to alter his/her knowledge of these words. A similar acquisition process occurs by using menus, selecting items, or following 
instructions in virtual pet, role-playing or action/adventure games. In Simulation Games, the player must vocally interact with the game via a microphone and use correct vocabulary, pronunciation or grammar, as well as speak appropriately in the game's context. If a player's utterance is incorrect, these games prompt the player to alter his/her utterance. This latter type of Simulation Game gives a learner numerous chances to improve his/her speaking ability and pronunciation through implicit feedback.

\section{2. Simulation Game Definition:}

A simulation game attempts to copy various activities in "real life" in the forr for various purposes: training, analysis, or prediction. Usually there are no strictly defined gu in the game, just running around, playing as a character. Well-known examples w var game business games, and role play simulation.

The comparisons of the merits of Simulation Games versus oth teac ing to iraes have been carried out by many researchers and a number of compreh e re nows ay been published. Simulations generally come in three styles: live, const active. A simulation also may be a combination of two or more styles.

Live simulations typically involve humans and/or equipm $t$ and tivity in a setting where they would operate for real. Think war games with ers out the field or manning command posts. Time is continuous, as in the real $\mathrm{w}$ fld. Another exar $/$ ple of live simulation is testing a car battery using an electrical tester.

Virtual simulations typically involve humans and equipment in a computer-controlled setting. Time is in discrete steps, allowing ars to com ale on the important stuff, so to speak. A flight simulator falls into this categ $y$.

Constructive simulations typically do not invo hum hor equipment as participants. Rather than by time, they are driven mor o, prope sequencing of events. The anticipated path of a hurricane might be "const ted" arough a plication of temperatures, pressures, wind currents and other weather ach ased simulations are typically constructive in nature.

\section{3. Hypothesis}

Navy Si Mulation Game is effect on better English vocabulary and pronunciation learning of rs ar arines of Khoramshahr Navy University.

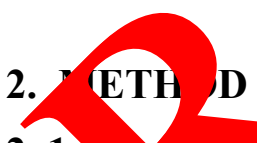

2. 1.

A th of 88 mariner students of Khoramshahr Navy University all male and with age range of 22 to 24 years participated in this experimental study. All of these participants were originally Iranian and English was a foreign language for them and Persian was the first language. The participants were recruited to voluntarily participate in an English language program by the use of Navy Simulator Games in Khoramshahr Navy University.

Prior to the program, the mariner students took an English proficiency test in vocabulary and pronunciation. According to the scores 60 students were ranked as low intermediate, 22 were ranked as intermediate, and 6 were ranked as high intermediate. For the need of this study the 60 participants ranked as low intermediate were held in the program. In the next steps they 
were asked in a questionnaire about their current program of studying English and it became clear that just four of them participate in other English learning program at the moment.

As a requirement of the research the four mentioned students were eliminated in the program and the rest, 56 students, entered the Navy Simulator Game English Learning Program (NSGELP). In the other steps, to divide students randomly in two class, they were ordered alphabetically and then every odd numbers were placed in class A, and every even numbers in class B. it is worth mentioning that class A was taught in Navy Simulator Game English Learning Program while class B was taught in an ordinary method.

\section{2. Materials}

For the purpose of this research, a commonly accepted definition of 1 Simulat Game materials was used. To consider all aspects of the games ther ave interactions with Institute for Simulation and Training (IST). They consul ed son wavy Simulator Games that were suitable for students with low intermedia glis prof ciency.

Finally they nominated Ship Simulation Extreme Collection sol blished same that owned lots of situation and contexts and appropriated for sents with w intermediate proficiency. For the class A, there were prepared a laborator wis comput s, all equipped with Navy Simulation Game. At last for analyzing data thed S version 16 was used. As the requirement of the research an Independent $t$ to st was used.

\section{3. Procedure}

The study was conducted in a 45 dayterm pern classes, A and B, offered by Navy University of Khoramshahr. Class A s were placed in a laboratory equipped with Navy simulator Game and the other group, $\mathrm{Cl}$. s B m aced in an ordinary English language class. The important thing here to mention is: ctore the starting to teach English vocabulary and pronunciation, the vocabular an ronunc tion of Ship Simulation Extreme was given to teachers to just work on them rder belimina some interfering factors. By so doing, there were one collection of wor ex

When the facilitie or both gr prepared, the instruction started. In the class A students learned technical voc ou expressy, and pronunciation through Simulator Games and in the other class stud wero rned those technical vocabulary, expression, and pronunciation in an ordinary y ay through the Cher pamphlet and instructions. In the class A after students played with mulati Games hey were asked to use the language they learned in the game. For instance, $\quad r$ of the eries of Ship Simulation Collection, students played on a stormy situationd cor

The hey we sked to use it in front of the class. It had much interest when they were div in ceveral groups and each group was responsible for role playing a specific part. In the ot sass tin same procedure was run with just the difference of instruction. At the end of 45 days a oficiency test was conducted on both groups. The test was based on the standard of English, 1 vocabulary and pronunciation. The exam result then analyzed by Independent $t$ test. Findings are discussed in result section. 


\section{RESULT}

The scores are based on 100 questions in vocabulary (and expression), and pronunciation. The marks were given from 100 with 0 being the lowest and 100 being the highest mark. The score results of the final test in the class A and class B are presented in Table 1.

Table 1. Final Test Result in the Both Classes.

\begin{tabular}{|c|c|c|c|c|}
\hline & \multicolumn{2}{|c|}{ Class A } & Class B & \\
\hline Number & Vocabulary & Pronunciation & Vocabulary & \\
\hline 1 & 85 & 80 & 70 & \\
\hline 2 & 75 & 72 & 66 & \\
\hline 3 & 65 & 73 & 3 & \\
\hline 4 & 64 & 63 & & \\
\hline 5 & 72 & 91 & & 41 \\
\hline 6 & 50 & 82 & 80 & 50 \\
\hline 7 & 40 & 71 & 71 & 34 \\
\hline 8 & 43 & 65 & 5. & 67 \\
\hline 9 & 82 & 88 & 47 & 62 \\
\hline 10 & 81 & & 32 & 45 \\
\hline 11 & 59 & & 90 & 80 \\
\hline 12 & 45 & & 44 & 35 \\
\hline 13 & & 78 & 64 & 48 \\
\hline 14 & & 33 & 63 & 71 \\
\hline 15 & & 90 & 57 & 65 \\
\hline 16 & & 40 & 42 & 52 \\
\hline 17 & & 53 & 25 & 42 \\
\hline & & 64 & 16 & 40 \\
\hline & 0 & 50 & 43 & 34 \\
\hline & 55 & 42 & 18 & 46 \\
\hline & 89 & 38 & 60 & 58 \\
\hline & 80 & 40 & 40 & 68 \\
\hline & 70 & 45 & 15 & 62 \\
\hline 24 & 15 & 68 & 52 & 67 \\
\hline 25 & 76 & 81 & 41 & 70 \\
\hline 26 & 64 & 60 & 37 & 76 \\
\hline 27 & 55 & 52 & 45 & 34 \\
\hline 28 & 43 & 45 & 74 & 84 \\
\hline
\end{tabular}


Table 2 shows that class A was significantly different from class B on both English vocabulary and pronunciation learning through Navy Simulation Games $(p=.037 \& p=.02)$.

Table 2. Comparison of Class A\&B in English vocabulary and pronunciation learning.

\begin{tabular}{|c|c|c|c|c|c|}
\hline Variable & Mean & SD & $\mathbf{t}$ & df & p \\
\hline Vocabulary & & & 2.1 & 54 & .037 \\
\hline Class A & 61.03 & 19.44 & & & \\
\hline Class B & 49.89 & 19.44 & & & \\
\hline Pronunciation & & & 2.35 & 54 & \\
\hline Class A & 64.85 & 16.91 & & & \\
\hline Class B & 54.28 & 16.28 & & & \\
\hline
\end{tabular}
class A (61.03) is significantly higher than the score 9

The difference between the mean in class A\&B or vocabulary sceres is 11.14 that clearly indicate the significance of teaching vocabulary $b$, imulation ames, so the hypothesis is confirmed. The same interpretation is true about pron ation. $C$ ass A pronunciation average describes 64.85 is significantly higher than comparison of class $A \& B p=.037$ for voca trm $p=.02$ for pronunciation it is crystal clear that Simulation Game has effect on En lis voy oulary and pronunciation learning of Khoramshahr Navy University and hypothe is is well accepted.

The surprising thing in re re th sectio is the equal SD for both classes in both vocabulary and pronunciation ich success of division of students in both classes. It shows that part apants th classes have the same language proficiency.

\section{CONCLUSIO}

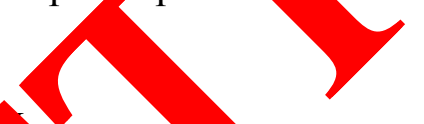

The of and study support the hypothesis that Game and specifically Simulation Gan ave a s gnificant effect on English vocabulary and pronunciation learning of sai 1 mar nus it is supporting the finding of previous investigations (Prensky, 20 Sea 1997; K riemuir, 2002). It was found that gains in knowledge of vocabulary and pron ir ed to be larger with the use of Navy Simulation Games. In one encounter, the par ants demonstrated large gains in knowledge of vocabulary and pronunciation in association Simulation Games. To survey the result it can be seen in several aspects. First and maybe the most important one is psychological aspect. The investigation of what makes Simulation Games fun offer interesting new light on what will motivate a language student to learn language (Armando Baltra, 2012).

Educational material that is fun is also intrinsicly motivating and should thus pave the way to successful learning. Intrinsic motivation is one of the foremost factors in second and foregin language learning and according to the result of this paper and other researches Simulation games can bring intrinsic motivation and facilitate second and foregin language learning( Brown 2007). The next thing to be consider is the emerging of new technologies. 
Young language learners in todays life are doing lots of their activites through new technologies and learning new language isn't exeption for them. So it is very boring for young learners to learn by the traditional ways. The last thing to mention that is more specificly in relation with our research topic is using this Simulation games will prepare pedegagical contexts for young sailors and mariners and in this way helps them to experince the real situation in a virtual environment. The thought of their work in sailing makes language learning an inductive and unconsciouse process. When the attention of the learner take away from the language it helps the learner to work on it in an unconsciouse way and learn language as ESP( english for specific purposes). What should be considered by lanuage planers is to plom ising this kind of games in ESP teaching to help learners to take advantage of both learnig lang and the pedegagical context of them.

\section{References}

[1] Agudo J. E., Sanchez H., Rico M. (2010). Playing games mouse interaction at early ages.

[2] Ahearn Nate. "Game Dev Story iPhone Review". IGN trieve ctober 18, 2010.

[3] Chuang T. Y., Chen W. F. (2007a). Digital game for cognitive leg. ning: a pilot study. Journal of Scientific and Technological Studies 1(1), 17-27

[4] Cordova D. I., Lepper M. R. (1996). Intrinsic mo tion an the process of learning: Beneficial effects of contextualization nersonalizm, and choice. Journal of Educational Psychology, 88, 715-730.

[5] Danny Saunders, Jacqui Severn. (1999). ". Mulatien and Games for Strategy and Policy Planning", p. 20

[6] deHaan J. (2011). Teachira d lo mino English through digital game projects. Digital Culture \& Education

[7] deHaan J., Reed Y. Kuwada 2010). The effect of interactivity with a music video game on s fond ruage vocabulary recall. Language Learning \& Technology, 14(2), 74-9

[8] Demirb M., mar E., Tamer S. (2010). Second language instructors' perspectives about the foduca onal games. Procedia Social and Behavioral Sciences, 9, 7170.

[97 onm s V. (201, J). The use of social networks in educational computer-game based ge learning. Procedia Social and Behavioral Sciences, 9, 1497-1503.

[10] Insu for Simulation \& Training, 3100 Technology Pkwy, Orlando, FL 32826 407-\& 2-1300; www.IST.com

[11] Ken Jones. (1995). "Simulations: A Handbook for Teachers and Trainers", ISBN 0-7494-1666-1, p. 21.

[12] Kirriemuir J. (2002). Video Games and Gaming Consoles. The relevance of video games and gaming consoles to the Higher and Further Education learning experience. Availablehttp://www.jisc.ac.uk/index.cfm?name=techwatch_report_0201 
[13] Kirriemuir J., McFarlane A. (2004). Literature review in games and learning. Futurelab, Online. http://www.futurelab.org.uk/research/lit_reviews.htm.

[14] Seay J. (1997). An Educator's Encounter. Education and Simulation/Gaming and Computers. Available: http://www.cofc.edu/ seay/cb/simgames.html

[15] Verdugo D. R., Belmonte I. A. (2007). Using digital stories to improve listening comprehension with Spanish young learners of English. Language Learning \& Technology, 11(1), 87-101.

[16] Wang Y. H. (2010). Using communicative language games in teaching and 1 English in Taiwanese primary schools. Journal of Engineering Technology and Education, 7(1), 126-142.

[17] Yip, F. W. M., Kwan, A. C. M. (2006). Online vocabulary games and learning English vocabulary. Educational Media Internation , 43(3) 233-2

[18] Zeynep Tanes Zeynep Cemalcilar (20 November 2009). empirical study of Turkish adolescents".

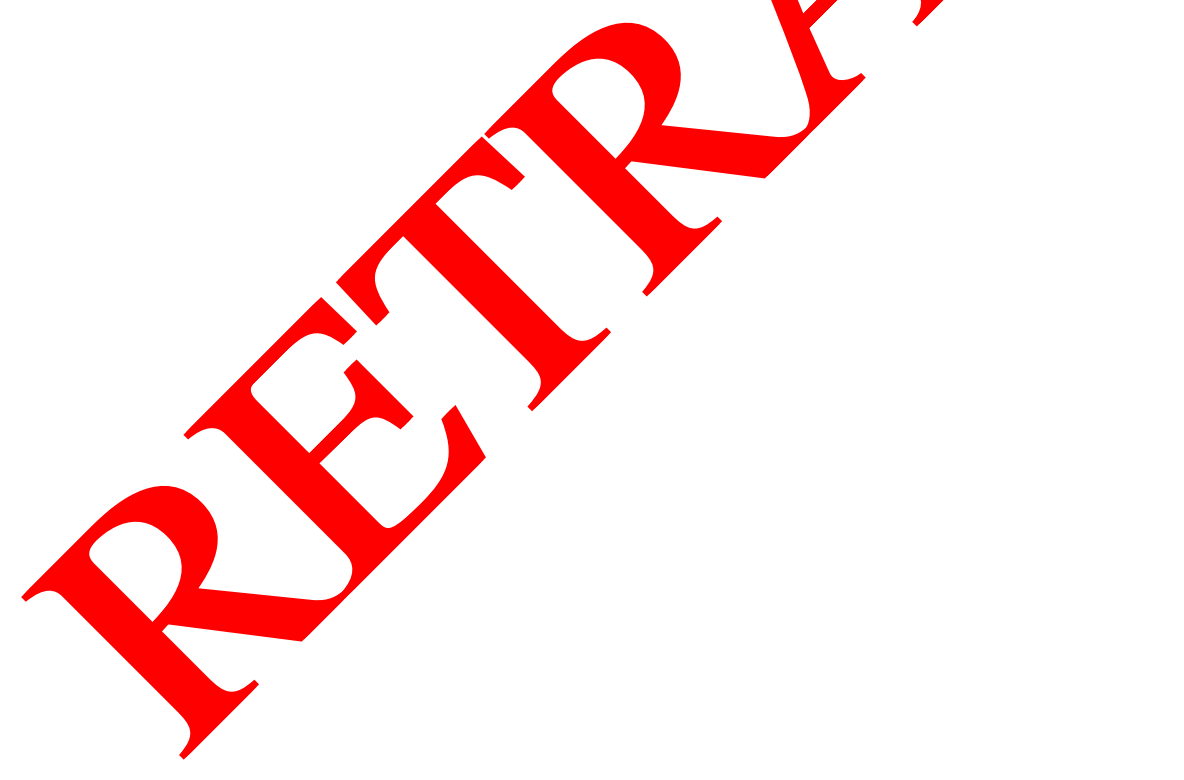

( Received 22 July 2013; accep 125 July 201) 